\title{
PENGGUNAAN METODE DISKUSI KELOMPOK UNTUK MEMAHAMI JURNAL KESEHATAN DITINJAU DARI RANAH KOGNITIF PADA MAHASISWA JURUSAN FISIOTERAPI
}

\author{
Noerdjanah, Jasmine Kartiko Pertiwi \\ Kementerian Kesehatan Politeknik Kesehatan Surakarta Jurusan Fisioterapi
}

\begin{abstract}
Cognitive Domain, Health Journal, Group Discussion. It is very important for physiotherapist to understand Journal and to know the development of theory and practice. Physiotherapist Learning process is based on evidence based so that they must understand the content of journal. Most students don't understand the content of journal. One of learning method that can used for understanding of journal is group discussion. This study is interested in the class research action which the title is Using Group Discussion Method for understanding Health Journal from cognitive domain to Physiotherapy student of Health Polytechnic of Surakarta. Research Objective is to recognize the achievement of ability to understand the content of journal in cognitive domain of English Lesson in group discussion of Physiotherapy student of Health Polytechnic of Surakarta. The construction of research that be used by the class research action (PTK), Subject are 65 student in eight groups. The research is hoped to be benefit for researcher and can be used as basic reference of research deeply.
\end{abstract}

Keywords : Cognitive Domain, Health Journal, Group Discussion

Abstrak: Domain Kognitif, Jurnal Kesehatan, Diskusi Kelompok. Sangat penting bagi fisioterapis untuk memahami Jurnal dan mengetahui perkembangan teori dan praktik. Proses Belajar Fisioterapis didasarkan pada bukti sehingga mereka harus memahami isi jurnal. Sebagian besar siswa tidak memahami isi jurnal. Salah satu metode pembelajaran yang dapat digunakan untuk memahami jurnal adalah diskusi kelompok. Penelitian ini tertarik pada penelitian tindakan kelas yang judulnya Menggunakan Metode Diskusi Kelompok untuk memahami Jurnal Kesehatan dari domain kognitif ke mahasiswa Fisioterapi Politeknik Kesehatan Surakarta. Penelitian Objektif adalah untuk mengetahui pencapaian kemampuan memahami isi jurnal dalam domain kognitif pelajaran bahasa Inggris dalam diskusi kelompok mahasiswa Fisioterapi Politeknik Kesehatan Surakarta. Konstruksi penelitian yang digunakan oleh kelas tindakan penelitian (PTK), Subjek adalah 65 siswa dalam delapan kelompok. Penelitian ini diharapkan dapat bermanfaat bagi peneliti dan dapat dijadikan referensi dasar penelitian secara mendalam.

Kata Kunci: Domain Kognitif, Jurnal Kesehatan, Diskusi Kelompok

\section{PENDAHULUAN}

Pemahaman jurnal sangat penting

bagi tenaga kesehatan khususnya

Fisioterapi untuk mengikuti perkembangan ilmu pengetahuan baik secara teoris dan praktis. Lebih-lebih pembelajaran fisioterapi saat ini ditekan dan pada eviden base maka pemahanan 
jurnal saat ini sangat diperlukan. Namun pada kenyataannya mahasiswa masih jauh untuk menguasai isi jurnal. Berbagai motode pembelajaran dapat diterapkan dalam pemahaman jurnal, seperti metode diskusi kelompok. Dalam Kamus Besar Bahasa Indonesia (2007: 125) Diskusi adalah pertemuan untuk bertukar pikiran mengenai suatu masalah. Metode diskusi kelompok ini, di pilih karena memiliki keunggulan yaitu sebagai latihan permulaan yang bertujuan untuk melatih kemampuan berbicara mahasiswa, melibatkan setiap individu berbicara lebih efektif, mengurangi kejenuhan sehingga membuat mahasiswa menjadi tidak bosan dan dapat menumbuhkan motivasi bagi mahasiswa dalam belajarnya. Disamping itu juga, dengan diskusi kelompok mahasiswa yang pasif dapat dirangsang supaya aktif berbicara serta melatih mahasiswa berpikir secara logis sehingga mudah dalam memahami jurnal kesehatan. Berdasarkan pengertian jurnal penelitian, fungsi dan ciri-cirinya maka peneliti tertatik untuk melakukan Penelitian Tindakan Kelas (PTK) dengan judul Penggunaan Metode Diskusi Kelompok untuk Memahami Jurnal Kesehatan Ditinjau dari Ranah Kognitif pada Mahasiswa Jurusan Fisioterapi Poltekkes Kemenkes Surakarta.

\section{METODE PENELITIAN}

Data yang diperlukan adalah data kuantitatif. Data Kuantitatif diperoleh dari rumus mean dan ketuntasan belajar.

\section{Data Kuantitatif}

Data kuantitatif diperoleh dari rumus mean dan rumus ketuntasan belajar. Menurut Sugiyono (2003: 47), menghitung rata-rata menggunakan rumus mean yaitu:

$$
\Sigma \text { fiXi }
$$

$$
X=\frac{}{\Sigma \text { fi }}
$$

Keterangan:

$\mathrm{X}=$ Nilai rata-rata hitung

$\Sigma$ fiXi $=$ Total Nilai interval kelas

$\Sigma$ fi $=$ Frekuensi interval kelas

Ketuntasan belajar Bahasa Inggris yang ditentukan di Jurusan Fisioterapi Poltekkes Surakarta adalah 65. Suhardi R (2012) menyatakan

rumus menghitung persentase ketuntasan belajar mahasiswa secara

klasikal yaitu:

$$
\mathrm{TB}=\frac{\Sigma \mathrm{s} \geq 65}{\mathrm{~N}}
$$

Keterangan:

$\Sigma \mathrm{s} \geq 65$ = Jumlah mahasiswa yang mendapat nilai lebih besar dari atau sama dengan 65

$\mathrm{N}=$ Banyak mahasiswa

$100 \%=$ Bilangan tetap

$\mathrm{TB}=$ Ketuntasan belajar

\section{HASIL PENELITIAN}

Berdasarkan hasil penelitian diketahui kemampuan memahami isi jurnal kesehatan mahasiswa Jurusan Fisioterapi Poltekkes Kemenkes Surakarta, rata-rata sebesar 49.23, dengan variansi 331.43. Hasil prestasi kemampuan memahami isi jurnal kesehatan mahasiswa ternyata masih dibawah KKM yang ditetapkan oleh fihak jurusan yaitu 65. Hal ini menjadi alasan dosen untuk melakukan penelitan dengan menggunakan metode diskusi kelompok.

\section{PEMBAHASAN}

\section{A. Siklus I}

Perencanaan. Langkah-langkah dosen

a. menyusun materi pelajaran 
b. mempersiapkan materi media pembelajaran

c. mempersiapkan pembelajaran

Pelaksanaan

1. membuat kelompok belajar

2. menentukan penanggung jawab kelompok belajar

Refleksi, berdasarkan hasil

pelaksanaan tindakan siklus 1 , diperoleh

nilai rata-rata sebesar 51.15 dan variansi

sebesar 364.86. sebagaimana kondisi awal ada peningkatan nilai kemampuan mahasiswa dalam memahami isi jurnal

kesehatan. Berikut tabel perbedaan nilai kemampuan mahasiswa dalam memahami isi jurnal kesehatan pada kondisi awal dengan siklus I.

\section{Tabel 1}

Kemampuan Mahasiswa Dalam Memahami Isi Jurnal Kesehatan

\begin{tabular}{lll}
\hline & Kondisi Awal & Siklus I \\
\hline Mean & 49.23 & 51.154 \\
Variance & 331.43 & 364.84 \\
Observations & 65 & 65 \\
\hline
\end{tabular}

Pada table di atas, rata-rata awal kemampuan mahasiswa dalam memahami isi jurnal kesehatan adalah 49.23 dan pada siklus 1 sebesar 51.154. Artinya ada peningkatan sebesar 1,92 , peningkatan ini perlu ditindak lanjuti dengan tindakan siklus II. Untuk memperkuat keputusan melakukan siklus II, dilakukan uji beda. Berdasarkan hasil uji beda diketahui sebagaimana table berikut.

Tabel 2

t-Test: Paired Two Sample for Means

\begin{tabular}{lll}
\hline & Kondisi Awal & Siklus I \\
\hline Mean & 49.23076923 & 51.1538462 \\
Variance & 331.4302885 & 364.858774 \\
Observations & 65 & 65 \\
Pearson & & \\
Correlation & 0.171089508 & \\
Hypothesized & & \\
Mean Difference & 0 & \\
Df & 64 & \\
t Stat & -0.645287204 & \\
P(T<=t) one-tail & 0.260523894 & \\
t Critical one-tail & 1.669013026 & \\
P(T<=t) two-tail & 0.521047788 & \\
t Critical two-tail & 1.997729633 & \\
\hline \multicolumn{2}{c}{ Berdasarkan hasil uji beda }
\end{tabular}

Berdasarkan hasil uji beda, diketahui bahwa nilai kondisi awal dengan siklus I tingkat keberartiannya sebesar 0.260. Hal ini menunjukkan bahwa tidak ada perbedaan yang signifikan antara kondisi awal dengan siklus I.

\section{B. Siklus II}

Perencanaan

1) Dosen menjelaskan materi pelajaran yang dipelajari

(2) Dosen membentuk 13 kelompok diskusi, setiap kelompok terdiri dari 5 orang mahasiswa.

(3) Dosen menyampaikan cara pelaksanaan diskusi kelompok

(4) Dosen menentukan tujuan dari diskusi kelompok kepada

(5) Dosen memberikan ruang untuk melakukan tanya jawab terhadap materi yang telah disampaikan.

(6) Setelah tanya jawab selesai dilakukan maka dibuatlah kesimpulan dari hasil-hasil diskusi kelompok tersebut

Pelaksanaan

1. membuat kelompok belajar

2. menentukan penanggung jawab kelompok belajar 
Refleksi, berdasarkan hasil pelaksanaan tindakan siklus II, diperoleh nilai rata-rata sebesar 94.42 dan variansi sebesar 63.62. sebagaimana kondisi awal ada peningkatan nilai kemampuan mahasiswa dalam memahami isi jurnal kesehatan. Berikut tabel perbedaan nilai kemampuan mahasiswa dalam memahami isi jurnal kesehatan pada siklus I dengan siklus II.

Tabel 3

\section{Kemampuan Mahasiswa Dalam} Memahami Isi Jurnal Kesehatan Pada Siklus I Dengan Siklus II

\begin{tabular}{lll}
\hline & Siklus I & Siklus II \\
\hline Mean & 51.15384615 & 94.4230769 \\
Variance & 364.858774 & 63.6268029 \\
Observations & 65 & 65 \\
\hline
\end{tabular}

Pada table di atas, rata-rata siklus 1 kemampuan mahasiswa dalam memahami isi jurnal kesehatan adalah 51.153 dan pada siklus II sebesar 94.423. Artinya ada peningkatan sebesar 43,26, peningkatan ini cukup besar. Berdasarkan hasil uji beda diketahui sebagaimana table berikut.

\section{Tabel 4}

t-Test: Paired Two Sample for Means

\begin{tabular}{lll}
\hline & Siklus I & Siklus II \\
\hline Mean & 51.15384615 & 94.4230769 \\
Variance & 364.858774 & 63.6268029 \\
Observations & 65 & 65
\end{tabular}

Pearson

Correlation

$-0.165411907$

Hypothesized

Mean Difference 0

Df 64

t Stat

$(15.941)$

$\mathrm{P}(\mathrm{T}<=\mathrm{t})$ one-tail

0.000

t Critical one-tail

1.669

$\mathrm{P}(\mathrm{T}<=\mathrm{t})$ two-tail

0.000

t Critical two-tail

1.998

Berdasarkan hasil uji beda, diketahui bahwa nilai kondisi awal dengan siklus I tingkat keberartiannya sebesar
0.000. Hal ini menunjukkan bahwa tidak ada perbedaan yang signifikan antara kondisi awal dengan siklus I.

\section{KESIMPULAN DAN SARAN}

Berdasarkan hasil pelaksanaan tindakan siklus 1 , diperoleh nilai rata-rata sebesar 51.15 dan variansi sebesar 364.86. sebagaimana kondisi awal ada peningkatan nilai kemampuan mahasiswa dalam memahami isi jurnal kesehatan.

Pada siklus 1 kemampuan mahasiswa dalam memahami isi jurnal kesehatan adalah 51.153 dan pada siklus II sebesar 94.423. Artinya ada peningkatan sebesar 43,26, peningkatan ini cukup besar

Ada peningkatan kemampuan mahasiswa dalam memahami isi jurnal menggunakan metode diskusi kelompok.

Untuk meningkatkan kemampuan mahasiswa dalam memahami isi jurnal kesehatan, ada beberapa saran yang perlu diperhatikan dalam mata pelajaran Bahasa Inggris yaitu: Bagi dosen diharapkan agar dapat memberikan motivasi kepada mahasiswa untuk meningkatkan kemampuan mahasiswa dalam memahami isi jurnal kesehatan dengan menggunakan metode diskusi kelompok, Bagi Dosen diharapkan agar dapat lebih kreatif dalam proses pembelajaran dikelas, salah satunya dengan menggunakan metode diskusi kelompok yang dapat meningkatkan kemampuan mahasiswa dalam memahami isi jurnal kesehatan.

\section{DAFTAR RUJUKAN}

Sudjono, Anas. 2008. Pengantar Evaluasi Pendidikan. Jakarta: PT.RajaGrafindo Persada.

Sumber : ejournal.comKontributor : Mia Audini (Staff Departemen 
Penelitian dan Pengembangan

BEM FKB 2016)

Sanjaya, Wina. 2011. Strategi pembelajaran berorientasi standar proses pendidikan. Jakarta: Kencana Prenada Media.

Slameto. 2010. Belajar dan Faktor-Faktor Mempengaruhinya. Jakarta: Rineka Cipta.

Sugiyono. 2007. Metode Penelitian dan statistik untuk penelitian. Bandung:

Alfabeta.

Sugiyono. 2009. Metode Penelitian Kuantitatif Kualitatif dan $R \& D$. Bandung: Alfabeta.

Suhartin, R.I. 1982, Prinsip-prinsip dan Teknik Berkomunikasi. Jakarta: Bhrata KrayaAksara.

Simamora, Roymond. 2009/Buku Ajar Pendidikan dalam Keperawatan. Jakarta: $E G C$ 